\title{
XRD, Thermal, Haemolysis and DNA Binding Studies of L-Arginine Functionalized Hydroxyapatite Nano- particles
}

\begin{abstract}
Hydroxyapatite (HAP), an important bio-mineral, finds numerous applications in the clinical field. As amino acids exhibit synergetic effects on structure, morphology and several bio-logical properties of HAP, an attempt was made by the present authors to synthesize pure and different amount of L-arginine functionalized HAP nano-particles by the surfactant mediated approach. The samples were characterized by using different techniques, viz., powder X-Ray Diffraction (powder XRD), Fourier Transform Infrared (FT-IR) spectroscopy, Transmission Electron Microscopy (TEM) and Thermo-Gravimetry Analysis (TGA). The Williamson and Hall (W-H) analysis was performed on the powder XRD patterns, which indicated the particle size in nano-meter range and the strain associated with nano- particles changed with functionalization of HAP by L-arginine. FTIR study indicated the presence of various functional groups due to the functionalization of L-arginine with HAP. TGA results indicated slightly poor thermal stability of L-arginine functionalized HAP samples with comparison to pure HAP. The DNA binding studies indicated improved DNA binding on L-arginine functionalization of HAP. The haemolysis studies were also carried out.
\end{abstract}

Keywords: Hydroxyapatite; Functionalization; Powder XRD; FTIR; TGA; DNA binding; Haemolysis

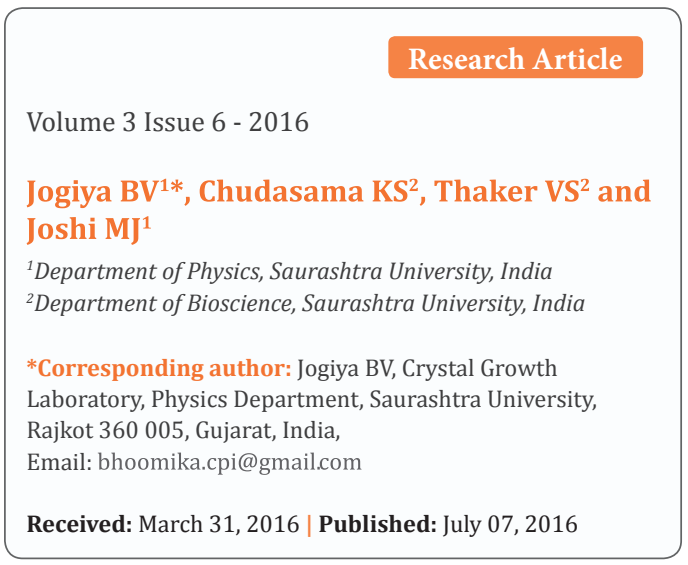

Abbreviations: HAP: Hydroxyapatite; FT-IR: Fourier Transform Infrared; TEM: Transmission Electron Microscopy; W-H: Williamson and Hall; XRD: X-Ray Diffraction; TGA: ThermoGravimetry Analysis; dsDNA: Double-Stranded Deoxyribonucleic Acids; OD: Optical Density; ssDNA: Single Stranded DNA

\section{Introduction}

Hydroxyapatite or HAP $\left(\mathrm{Ca}_{10}\left(\mathrm{PO}_{4}\right)_{6}(\mathrm{OH})_{2}\right)$ is a well known biomineral and finds numerous applications in medicinal field as well as industrial field, for example, coatings in dental implants [1], bone implants facilitating bone formation $[2,3]$ chromatographic separation of protein and DNA [4], protein purification [5], gene delivery [6], catalysis [7], gas sensing [8], $\mathrm{H}_{2} \mathrm{O}_{2}$ fuel cell [9] etc. In addition, HAP inhibits the proliferation and apoptosis of cancerous cells [10-12]. Several books and review papers are available on HAP and its applications [13-17]. It is non toxic, anti inflammatory and highly bio-compatible material. Marchi et al. [18] have examined the in vitro interaction of human fibroblast cells with HAP as well as alumina and observed better biocompatible nature of HAP compared to alumina.

Presently, the targeted gene and drug delivery is on the prime focus in medicinal research. As early as in 1970s, the defected DNA was replaced by normal DNA in a patient suffering from genetic disorder [19]. In succession to this, in the last 25 years, several successful gene transfer experiments have been reported in the treatment of various diseases and a few noteworthy recent attempts are in the diseases like Parkinson [20] Chronic granulomatous [21] and several retinal diseases [22]. Recently, promising results are also recorded in gene therapy for treatment of HIV [23]. Technically, the gene therapy is accomplished by using either viruses or biological nano-particles as gene delivery vectors [6]. However, the viral/former therapy may sometimes cause immune response that leads to dangerous infections [24] and hence it will be safer to use non-viral and bio-compatible vectors for gene therapy $[6,25,26]$. In this regard the HAP has been preferred as a better alternative due to its high bio-compatible nature [27]. Therefore, the nano-particles of HAP finds novel applications in medicine, for instance, HAP as non-viral vectors for efficient In vivo gene delivery [28], celecoxib-loaded HAPchitosan nano-composite for colon cancer treatment [28], effect of HAP uptake into hepatoma cells for inhibitory effect on liver cancer metastasis [29] and mineralization of DNA into nanoparticles of HAP [30]. However, relatively low efficiency of gene delivery is one of the major problems for using the HAP in clinical trials. Recently, some researchers have revealed that hydrophilic L-arginine with guanidyl group $\left(\mathrm{CH}_{2}\right) 3 \mathrm{NHC}\left(\mathrm{NH}_{2}\right)^{+}$could enhance the gene delivery efficiency of HAP [31].

The functionalization of the HAP nano-particles by amino acids has synergetic effects on their structural, morphological and surface properties [32]. Functionalizing HAP with amino acids has resulted in to high protein adsorptive capacity [32]. The effects of various amino acids on the particle size and morphology of HAP nano-particles along with their physical characterizations are reported [32-35]. In the earlier studies from our laboratory, Tank et al. [36] have carried out antimicrobial and haemolysis 
study of cobalt doped nano HAP to confirm its safe application in the medical field. After considering the benefits of HAP nanoparticles as a gene delivery agent, in this investigation the authors aim to synthesize pure and functionalized HAP nano-particles with different amount of amino acid L-arginine and characterized them by Powder XRD, TEM and TGA, haemolysis and DNA binding to identify their possible biological applications.

\section{Materials and Methods}

The HAP nano-particles were synthesized by the surfactant mediated approach. Calcium nitrate hexa-hydrate $\left(\mathrm{Ca}\left(\mathrm{No}_{3}\right)_{2} 6 \mathrm{H}_{2} \mathrm{O}\right)$, potassium dihydrogen phosphate $\left(\mathrm{KH}_{2} \mathrm{PO}_{4}\right)$, Triton $\mathrm{X}-100$, aqueous ammonia (all AR grade) were used as precursors. Initially, $2 \mathrm{ml}$ of Triton X-100 was mixed with $100 \mathrm{ml}$ of $0.3 \mathrm{M}$ calcium nitrate hexa-hydrate aqueous solution and, thereafter, the $100 \mathrm{ml}$ of $0.18 \mathrm{M}$ potassium dihydrogen phosphate aqueous solution was added and the mixture was treated with aqueous ammonia to set the $\mathrm{pH} 9$ with constant stirring and heating at $60^{\circ} \mathrm{C}$ temperature. This resulted into milky white solution with precipitates. The precipitates were recovered by filtration (Whatman filter paper No. 1) and washed with the mixture of ethanol and de-ionized water and then dried in air at room temperature. The L-arginine functionalized HAP (Ar-HAP) nano-particles were synthesized by adding $100 \mathrm{ml}$ different concentrations of L-arginine aqueous solutions, viz., $0.3 \mathrm{M}, 0.6 \mathrm{M}, 0.9 \mathrm{M}$ and $1.2 \mathrm{M}$ concentration, to the solution of calcium nitrate hexa-hydrate before the addition of surfactant and, thereafter, the same experimental procedure was repeated. Here, calcium to phosphate ratio was maintained 1.67, while calcium to amino acid ratio was selected as 1:1, 1:2, 1:3 and 1:4 and the synthesized samples were labelled as 1-Ar-HAP, 2-ArHAP, 3-Ar-HAP and 4-Ar-HAP, respectively, and the pure sample as HAP.

\section{Characterization techniques}

The Powder X-ray Diffraction (XRD) study was carried out on Bruker AXS D8 Advance setup using $\mathrm{Cu}(\mathrm{K} \alpha 1)$ radiation and the data were analyzed by software Powder X. The average crystallite size and strain were calculated by applying Williamson and Hall analysis to the powder XRD patterns. The Transmission Electron Microscope (TEM) analysis was conducted to determine the morphology and size of synthesized nano-particles using TECNAIKA20 (Philips) setup operating at $200 \mathrm{kV}$ potential. Fourier Transform Infrared (FTIR) spectra were recorded on Thermo Scientific Nicolet 1510 in $\mathrm{KBr}$ media in the range of $400 \mathrm{~cm}^{-1}$ to $4000 \mathrm{~cm}^{-1}$. Thermo-Gravimetry Analysis (TGA) was carried out on LINSEIS 1400 in atmosphere of air at heating rate of $15^{\circ} \mathrm{C} / \mathrm{min}$.

\section{DNA extraction}

The DNA isolation was performed as per the process reported by Chudasama \& Thaker [37]. The bacterial cells were pelleted by centrifugation and re-suspended in $500 \mu \mathrm{l}$ of $10 \mathrm{mM}$ TrisEDTA (ethylene-diamine-tetra-acetic acid) buffer and, thereafter, treated with $30 \mu \mathrm{l}$ SDS (sodium dodecyl sulfate $10 \% \mathrm{~W} / \mathrm{V}$ ) and $2 \mu \mathrm{l}$ proteinase $\mathrm{K}(10 \mathrm{mg} / \mathrm{ml})$. This was mixed well and incubated for $1 \mathrm{~h}$ at $37^{\circ} \mathrm{C}$. Thereafter, $20 \mu \mathrm{l}$ of cetyltrimethyl ammonium bromide $(10 \%, \mathrm{~W} / \mathrm{V})$ and $100 \mu \mathrm{l}$ of $\mathrm{NaCl}(5 \mathrm{M})$ were added, and incubated for 10 minutes at $65^{\circ} \mathrm{C}$. The DNA was purified by two
1:1 extractions in which, (i) chloroform: Isoamyl Alcohol (24:1) and (ii) Phenol: Chloroform: Isoamyl Alcohol (25:24:1) were used and then it was precipitated with iso-propanol, washed with ethanol (70\%), and dissolved in tris-EDTA buffer. The quality and concentration of the DNA was confirmed by measuring optical density at $260 / 280 \mathrm{~nm}$ ratio. The experiment was carried out in the aseptic medium.

\section{DNA binding}

For the DNA binding test, $50 \mathrm{mg}$ of pure and L-arginine functionalized HAP (Ar-HAP) samples were taken. The DNA binding generally involves three steps, viz., equilibrium, load, and elution. The columns were attached to a $60^{\circ} \mathrm{C}$ circulating water bath and rinsed twice with $1 \mathrm{ml}$ of $0.12 \mathrm{M}$ phosphate buffer of $\mathrm{pH}$ 6.8 before use. The samples were pre-equilibrated in $2 \mathrm{ml}$ of $0.12 \mathrm{M}$ phosphate buffer of $\mathrm{pH} 6.8$. Thereafter, $2 \mathrm{ml}$ of well mixed hydrated HAP nano-particles sample was added to the column and allowed to settle for 15 minutes. The equilibration of the column was accomplished by washing it three times with $0.12 \mathrm{M}$ phosphate buffer of pH 6.8. A known concentration of dsDNA (DoubleStranded Deoxyribonucleic Acids) was used to test the binding with pure HAP nano-particles and Ar-HAP nano-particles. The nucleic acid sample was incubated in $200 \mu \mathrm{l}$ of $0.12 \mathrm{M}$ phosphate buffer of pH 6.8 at $60^{\circ} \mathrm{C}$ for at least 20 minutes before applying it to the HAP/Ar-HAP column. The binding with HAP and/Ar-HAP was allowed for 20 minutes. The DNA was eluted with a $1 \mathrm{ml}$ of $0.40 \mathrm{M}$ phosphate buffer of $\mathrm{pH} 6.8$ and centrifuged at $10000 \mathrm{rpm}$ for 10 minutes. The resulting supernatant was collected and used as DNA source. In the pallet, $1 \mathrm{ml}$ of $1.0 \mathrm{M}$ phosphate buffer of $\mathrm{pH}$ 6.8 was added to remove the remaining DNA from the materials. The $0.40 \mathrm{M}$ and $1.0 \mathrm{M}$ fractions containing dsDNA were mixed. The pooled fractions were extracted by equal volumes of phenolchloroform-isoamyl alcohol $(25: 24: 1)$ and then precipitated with isopropanol, washed with ethanol (70\%), and dissolved in $50 \mu \mathrm{l}$ tris-EDTA buffer. The DNA fragments were separated by electrophoresis through $1.0 \%$ agarose gel. The concentration of the DNA was confirmed by measuring optical density at $260 \mathrm{~nm}$ by using SPECORD 200 PLUS spectrophotometer.

\section{Haemolytic activity}

The haemolytic activity of pure HAP and Ar-HAP nanoparticles was investigated with fresh human blood collected in anticoagulant containing tube. $50 \mathrm{mg}$ of samples were immersed in $1 \mathrm{ml}$ extraction medium of sterilized physiological saline buffer and incubated at $37^{\circ} \mathrm{C}$ for 30 minutes under static condition. The human blood was diluted by $6 \mathrm{ml}$ sterilized physiological saline and $200 \mu \mathrm{l}$ of this diluted blood was then added to the tubes containing $50 \mathrm{mg}$ HAP and Ar-HAP samples in sterile saline solution and incubated for $60 \mathrm{~min}$ in water bath. Thereafter, each tube was centrifuged and then the absorbance of the supernatant was measured at $545 \mathrm{~nm}$. Here, the negative control was sterilized physiological saline, and the positive control was distilled water. The haemolytic ratio $(\mathrm{Z})$ was calculated using the following formula.

$$
z=\left(D_{t}-D_{n c}\right) \times \frac{100}{\left(D_{p c-} D_{n c}\right)}
$$


Where, $\mathrm{Z}$ is haemolytic ratio and $\mathrm{D}_{\mathrm{t}^{\prime}}, \mathrm{D}_{\mathrm{nc}}$ and $\mathrm{D}_{\mathrm{pc}}$ are the average absorbance of samples, negative controls and positive controls, respectively. When the values of $\mathrm{Z}$ are $>5,2-5$ and $0-2$, the corresponding haemolytic grade is haemolytic, slightly haemolytic and non-haemolytic, respectively.

\section{Results and Discussion}

The effect of amino acid functionalization on HAP was studied in terms of crystallinity by several workers $[32,33,35]$ and found that the crystallinity of HAP decreased with functionalization of amino acid. Figure 1 shows the powder XRD patterns of pure HAP and Ar-HAP samples. One can observe that the powder XRD patterns are not altered much for pure and 1-Ar-HAP samples. However, separate peaks at $29^{\circ} \mathrm{C}$ and $34.3^{\circ} \mathrm{C}$ start appearing in 3-Ar-HAP sample and become more clear in 4-Ar-HAP sample, which are indicated by asterics in the figure. This indicates that the functionalization by L-arginine does not distort HAP much up to 1-Ar-HAP sample and further functionalization is expected to add a separate phase, which can be assigned to the possible formation of brushite (JCPDS-04-0740). The brushite phase is expected to occur due to positively charged guanidine group of L-arginine competing with the calcium ion for binding with the anions, which leads to the deficiency of calcium and the presence of ample amount the $\left(\mathrm{HPO}_{4}\right)^{2}$ ions gives the brushite $\left(\mathrm{CaHPO}_{4}\right)$ phase. Due to small particle size and broadening of the XRD patterns it is not possible to resolve other peaks for brushite and L-arginine in the XRD patterns. The brushite phase formation in HAP is well discussed by Tank et al. [38]. The analysis of the powder XRD patterns indicated monoclinic structure.

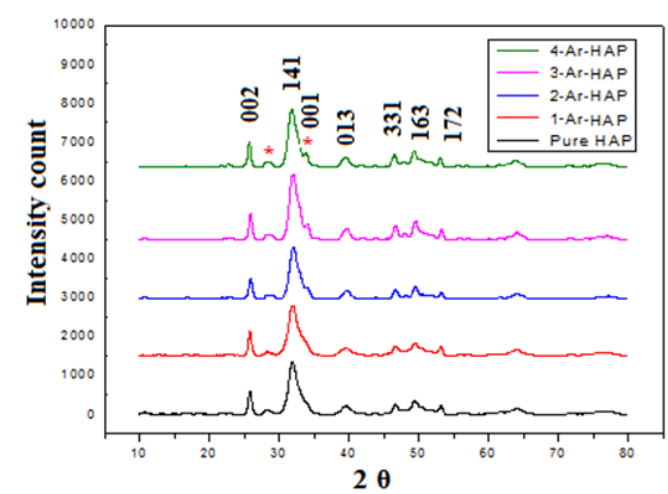

Figure 1: Powder XRD patterns of pure and L-arginine functionalized HAP samples.

Usually, the broadening of peaks in the powder XRD patterns is due to (i) the reduction in the crystallite domain, (ii) the presence of domains with lattice spacing differing from one to another and (iii) the presence of elastic deformations and stacking faults within the domains. To evaluate the contribution of crystallite size and micro-strain to the peak broadening of the powder XRD patterns, the present authors have employed the Williamson and Hall (W-H) analysis to the powder XRD patterns of (Figure 1) The W-H method considers both the limited crystallite size and the presence of crystallographic distortion or strain leading to the Lorentzian intensity distribution and can be written as follows:

$$
\beta \cos \theta=k \lambda / L+4 \eta \sin \theta
$$

Where, $\beta=$ Full width and half maximum (FWHM), L= Crystallite size, $\eta=$ Strain, $\mathrm{k}=0.9$ and $\lambda=1.54178 \AA$. The average particle size and strain was evaluated from the plots $\beta \cos \theta$ versus $4 \sin \theta$ by finding the intercept on the $y$-axis and the slope of the fitted linear plot [39,40].

Figure $2 \mathrm{a} \& 2 \mathrm{~b}$ shows the Williamson and Hall plots of the above relation for pure HAP and 4-Ar-HAP nano-particle samples, respectively, where, the slope indicates the value of strain. The average crystallite size and strain has been calculated for different samples and given in Table 1. It is found that L-arginine functionalization reduces the particle size of HAP nano-particles, while the strain is found to be increasing in the 1-Ar-HAP sample. But, for the sample 2-Ar-HAP the particle size and the strain both are increased, which may due to the presence of large number of positively charged guanidine group of L-arginine on the surface of HAP and their mutual interaction give rise of strain on the surface of HAP. On further increasing the proportion of L-arginine the particle size or crystallite size suddenly decreases and the strain increases due to more number of guanidine groups interacting with the surface and reducing the particle size and increasing correspondingly the strain. Finally, for the 4-Ar-HAP sample the particle size increases and the strain decreases; which may be attributed to the presence of a separate phase. The effect of functionalization of L-arginine on crystallinity is studied by defining the degree of crystallinity as:

$$
\text { Crystallinity }=100 \times C / A+C
$$

Where, $\mathrm{C}$ is the area of the peaks in the diffraction pattern, i.e., the crystalline area, and A is the area between the peaks and the back ground, i.e., the amorphous area. The values of $\mathrm{C}$ and $\mathrm{A}$ were calculated by using Powder X software. Table 1 gives the values of crystallinity and it is found that the crystallinity slightly decreases with increasing the L-arginine functionalization in HAP nanoparticles. This corresponds to earlier results of functionalization of HAP by amino acids [30]. However, for 4-Ar-HAP sample again higher degree of crystallinity is observed due to development of another phase as marked in the powder XRD pattern. The TEM (Figure 3a) images of amino acid functionalized HAP were earlier reported by several authors [32,33]. Figure $3 \mathrm{~b}$ exhibits the TEM image of 1-Ar-HAP sample and indicates the needle type morphology with reduced particle size. While, (Figure 3c3e) show the TEM images of 2-Ar-HAP, 3-Ar-HAP and 4-Ar-HAP samples, respectively, which show the spherical type morphology with particle size in 10 to $20 \mathrm{~nm}$ range. One can mark from the TEM images that the decrement in particle size as well as change in the morphology is occurring as the concentration of L-arginine increases. The needle type morphology exhibits higher growth rate in c-direction. The positively charged guanidine group of L-arginine binds with the negative hydroxyl group of HAP exposed on the surface in such a way that it produces some kind of capping and reducing the preferential growth in one direction and resulting in to spherical type morphology. 
Figure 4 shows the FTIR spectra of pure and L-arginine functionalized HAP samples. It confirms the presence of all the functional groups related to HAP. The absorption peaks located in the range of $3404-3440 \mathrm{~cm}^{-1}$ are due to the stretching mode of $\mathrm{O}-\mathrm{H}$. The characteristic band of the $\mathrm{PO}_{4}$ group of HAP was clearly observed in the spectrum. The vibrations of the asymmetric stretching mode of $\mathrm{PO}_{4}^{-3}$ were marked by $1034-1022 \mathrm{~cm}^{-1}$, while a small hump at $950 \mathrm{~cm}^{-1}$ exhibiting the stretching mode of $\mathrm{PO}_{4}^{-3}$. The medium absorption close to $600 \mathrm{~cm}^{-1}$ in the spectra was due to the 0-P-O bending mode [33]. Presence of the stretching modes of $\mathrm{NH}_{3}$ and $\mathrm{CO}_{2}$ were observed nearby $1455 \mathrm{~cm}^{-1}$ and $1460 \mathrm{~cm}^{-1}$. While an absorption observed at $1644 \mathrm{~cm}^{-1}$ represents the asymmetric stretching mode of $\mathrm{NH}_{3}$; which was getting overlapped with vibration of $\mathrm{H}_{2} \mathrm{O}$ at $1630 \mathrm{~cm}^{-1}$ [34] resulted in to the broadening of the peak. A weak hump observed at $2900-2800 \mathrm{~cm}^{-1}$ revealed the existence stretching mode of $\mathrm{C}-\mathrm{H}$ bond [34], which was absent in the FTIR spectrum of pure HAP. Hence, the FTIR spectra confirm the successful functionalization of the HAP by the L-arginine.
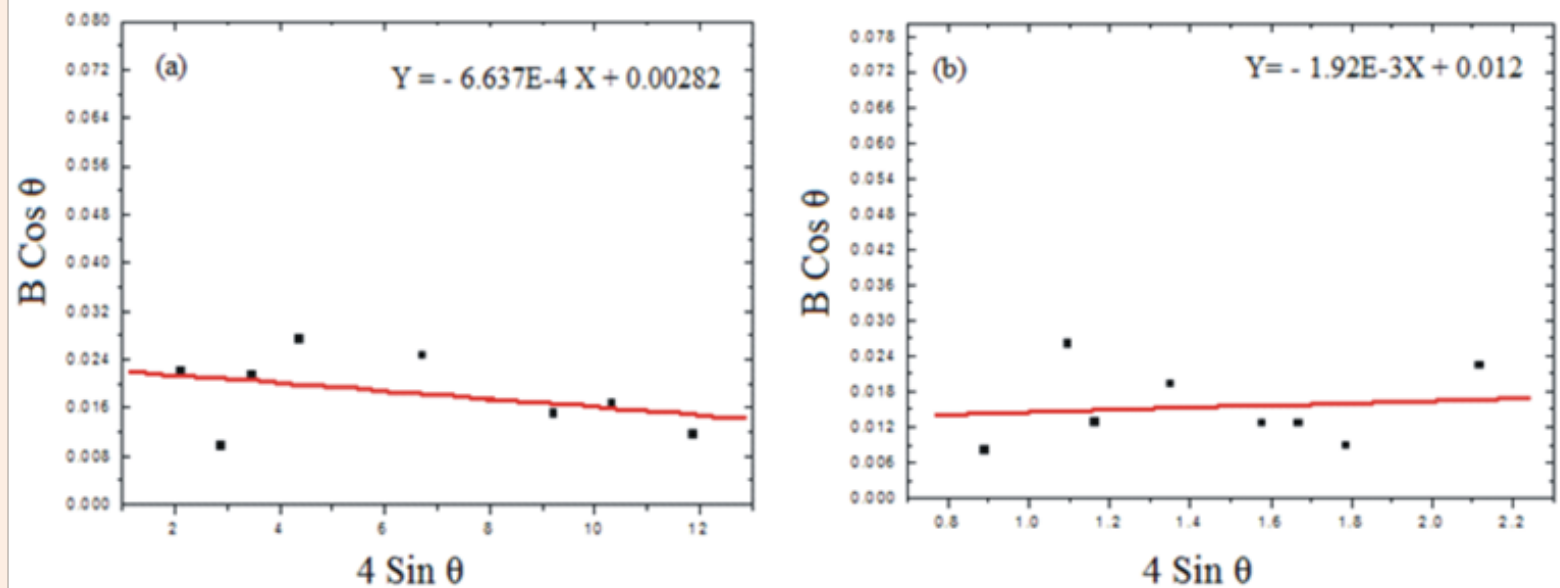

Figure 2: W-H plots of (a) Pure HAP and (b) 4-Ar-HAP.
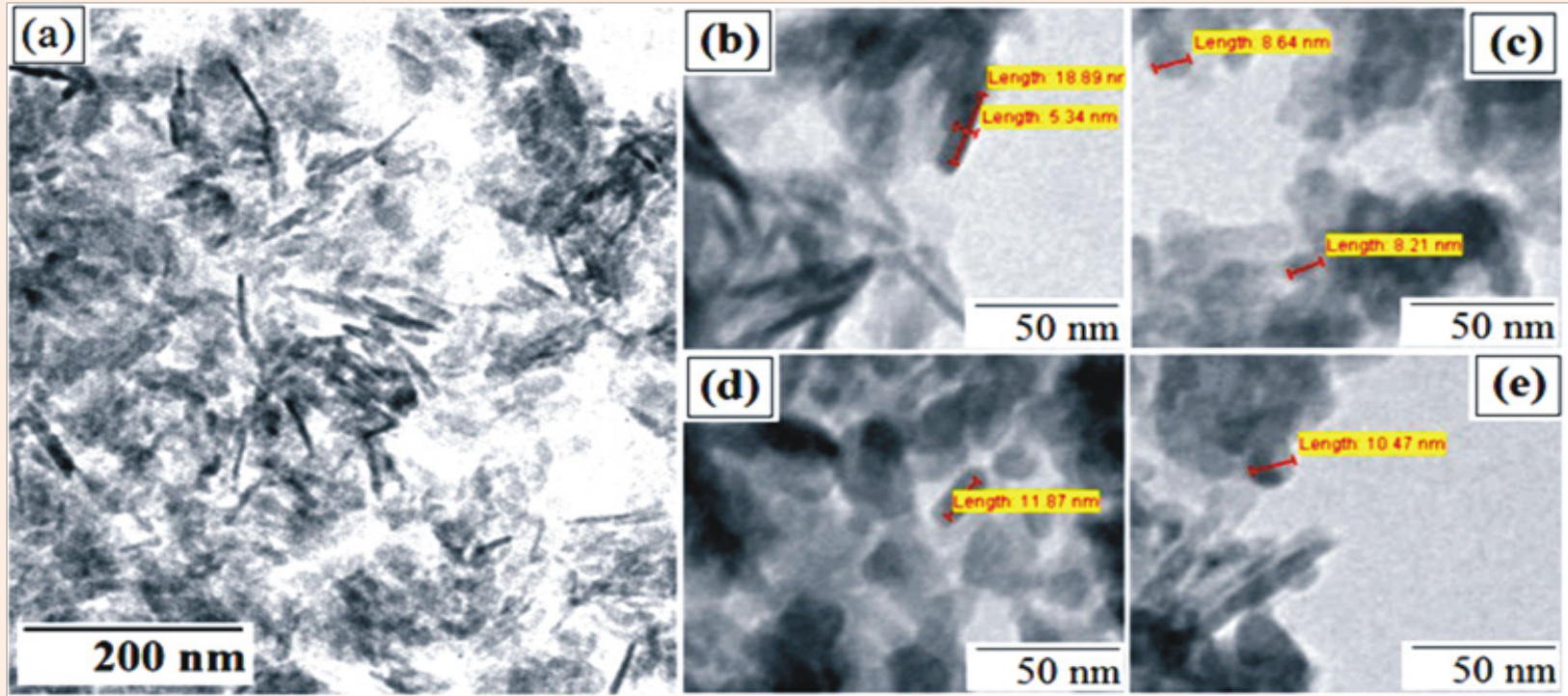

Figure 3: TEM images of (a) Pure HAP (b) 1-Ar-HAP (c) 2-Ar- HAP (d) 3-Ar-HAP (e) 4-Ar-HAP. 


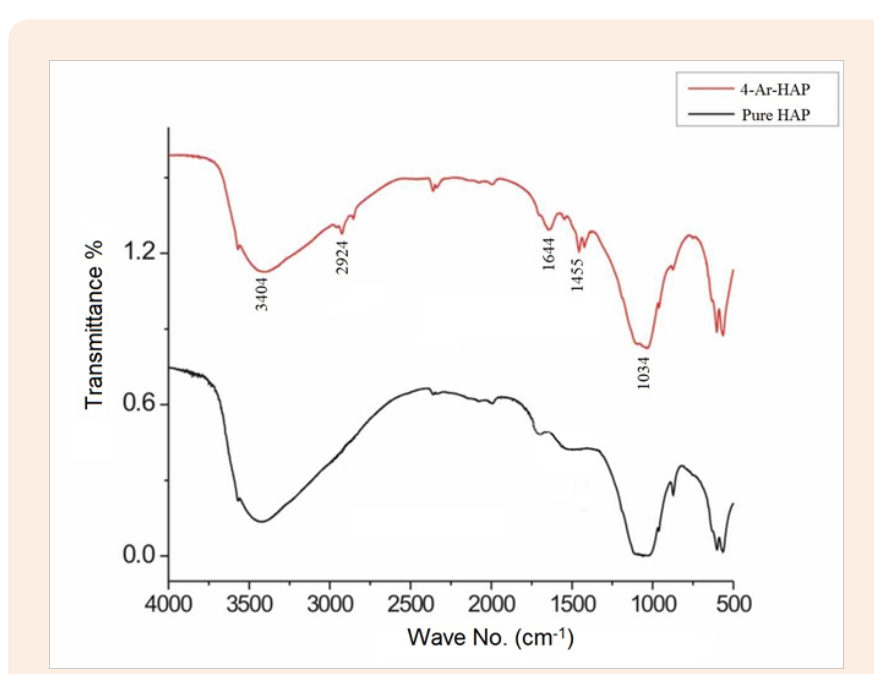

Figure 4: FTIR spectra of (a) Pure HAP (b) 4-Ar-HAP.

The thermal study of pure HAP and Ar-HAP nano-particles was carried out by using thermo-gravimetry to investigate the thermal stability of the samples. The thermal stability is an important parameter for physiological applications. The sample must remain thermally stable at physiological temperatures for safe and long term application. HAP is thermally very stable and reported well earlier [41]. Also, the thermal stability of calcium deficient HAP functionalized with different amino acids was reported [32] Table 2. Figure 5 shows the thermo-grams of pure and Ar-HAP samples. The samples exhibit the weight loss up to $600^{\circ} \mathrm{C}$ due to liberation of weakly and strongly absorbed water molecules [41]. The further weight loss from $600^{\circ} \mathrm{C}$ to $1200^{\circ} \mathrm{C}$ was due the gradual dehydration of HAP which is briefly discussed by Murray et al. [42] However, the enhanced weight loss in the Ar-HAP samples with comparison to pure HAP sample proves the presence of L-arginine. As L-arginine being organic material getting destabilized faster on heating and giving less thermal stability to the host material. Also, the residual mass of the samples at the end of the TGA at $1200^{\circ} \mathrm{C}$ is highest in the pure HAP and decreases progressively on increasing the amino acid L-arginine content in the samples, which further confirms the successful functionalization of the amino acid with HAP. This is further suggests the linking of guanidine group of the L-arginine to the crystal structure of HAP.

In vivo the haemolysis, i.e., the destruction of red blood cells, can leads to large number of serious diseases including anaemia and jaundice [43]. Therefore, it is essential to check the haemolysis response of a biomaterial for safer medical management. Recently, the haemolysis of pure HAP and cobalt, manganese, silver and zinc doped HAP has been reported $[36,38,41,44]$ and found to be nonhaemolytic and safe to use medically. In the present investigation, the haemolysis study was carried out for pure HAP and Ar-HAP nano material samples. Table 3 shows the Optical Density (OD) values of different samples for haemolysis study. The result shows that as the functionalization of L-arginine increases in HAP, the haemolytic ratio (Z) decreases from slightly haemolytic to nonhaemolytic grade. The least haemolytic ratio was observed in the sample 2-Ar-HAP.

Particularly, the HAP structure has attracted the attention of researchers for the application of protein purification and DNA separation. There are two different protein binding sites on the surface of HAP, i.e., $\mathrm{C}$ and $\mathrm{P}$ sites. The $\mathrm{C}$ site is rich in $\mathrm{Ca}^{2+}$ and exposed on the surface due to the dissolution of $\mathrm{OH}^{-}$in an aqueous solution and hence it strongly binds to the negatively charged $\mathrm{COO}^{-}$group of amino acid, whereas, the $\mathrm{P}$ site is rich in $\mathrm{PO}_{4}{ }^{3-}$ and interacts with positively charged groups, e.g., $\mathrm{NH}^{3+}$ group $[33,45]$. The functionalization of HAP with amino acids can alter the surface charges due to the presence of $\mathrm{COO}^{-}, \mathrm{NH}^{3+}$ and side groups in amino acids. The aspartic acid incorporation on the HAP surface enhances the adsorption of basic proteins owing to additional $\mathrm{COO}^{-}$groups on HAP due to aspartic acid [46]. The HAP is extensively used for the separation of ssDNA (Single Stranded DNA) and dsDNA (Double Stranded DNA). Andrews-Pfannkoch et al. [47] examined the effects of various binding parameters. The isotherm analysis suggested that the electrostatic forces are the main driving force of dsDNA binding to HAP. Because of the hydrophobic bases and the negative charge associated with the phosphate backbone, the dsDNA molecule binds to HAP with hydrophobic and electrostatic interactions.

In the present investigation, the bacterial double stranded genomic DNA (linear) was selected for binding to the pure HAP and Ar-HAP nano-particles. The agarose gel electrophoresis confirmed that the pure HAP and Ar-HAP samples were successfully bound with DNA and formed L-arginine-HAP-DNA complex. As shown in Figure 6, lane 1 contains the control DNA, while the lanes 2-5 contain the pure HAP, 1-Ar-HAP, 2-Ar-HAP, 3-Ar-HAP and 4-Ar-HAP sample-DNA complexes, respectively; demonstrating that the dsDNA is completely bound with pure HAP and functionalized HAP. The concentration of dsDNA was measured by $260 \mathrm{~nm}$ wavelength and compiled in Table 4 which shows that the DNA is maximum bound with 1-Ar-HAP nanoparticle sample compared to the 4-Ar-HAP, 3-Ar-HAP, 2-Ar-HAP and Pure HAP nano-particles. With comparison to the pure HAP, the DNA binding efficacy is more in functionalized samples, which may due to the enhanced interaction between DNA and hydrophilic L-arginine with a guanidine group on the surface of HAP. The comparative decrease in the DNA binding on increasing L-arginine content may be due to large number of its binding on HAP surfaces and the presence of large number of $\mathrm{COO}^{-}$and $\mathrm{NH}^{3+}$ groups and side chains inviting further competition within themselves to bind with DNA and only some of them are successful in achieving that; while for sample 1-Ar-HAP the situation seems to be quite conducive and optimum nature of DNA binding is obtained. In general, the L-arginine functionalized HAP possesses better DNA binding efficacy than the pure HAP. One can conclude from the study that the 1-Ar-HAP sample is the best one with the maximum DNA efficacy for in vitro applications, but it possesses slight haemolytic property. While the samples 2-Ar-HAP, 3-ArHAP and 4-Ar-HAP possess slightly less DNA efficacy but exhibit non haemolytic nature with safer medical use. 


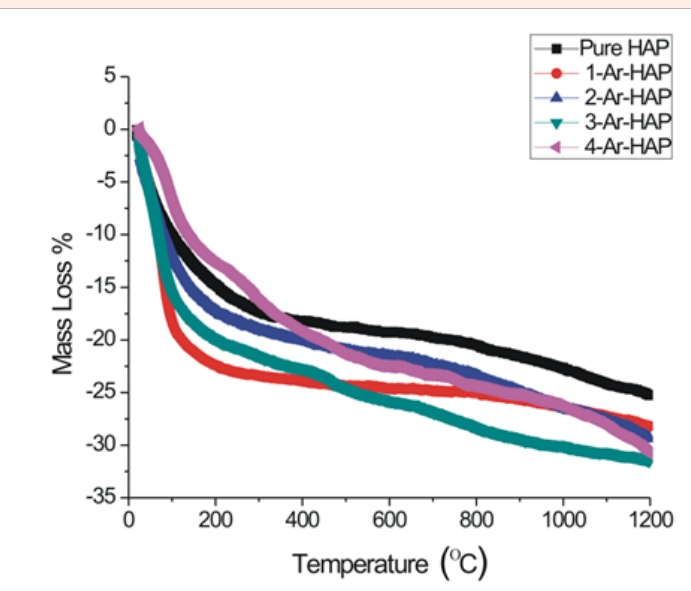

Figure 5: Thermo gram of (a) Pure HAP, (b) 1-Ar-HAP, (c) 2-Ar-HAP, (d) 3-Ar-HAP, (e) 4-Ar-HAP.

Table 1: Crystallite size, Strain and Crystallinity using W-H method.

\begin{tabular}{|c|c|c|c|c|}
\hline Sr. No & $\begin{array}{c}\text { Sample } \\
\text { Name }\end{array}$ & $\begin{array}{c}\text { Crystallite } \\
\text { Size }\end{array}$ & $\begin{array}{c}\text { Strain } \\
\mathbf{( 1 0}^{-3} \mathbf{)}\end{array}$ & Crystallinity \\
\hline 1 & Pure HAP & $49 \mathrm{~nm}$ & 0.16 & $61 \%$ \\
\hline 2 & 1-Ar-HAP & $6 \mathrm{~nm}$ & 3.1 & $56 \%$ \\
\hline 3 & 2 -Ar-HAP & $13 \mathrm{~nm}$ & 4.83 & $52 \%$ \\
\hline 4 & 3-Ar-HAP & $7 \mathrm{~nm}$ & 6.41 & $53 \%$ \\
\hline 5 & 4-Ar-HAP & $11 \mathrm{~nm}$ & 1.91 & $59 \%$ \\
\hline
\end{tabular}

Table 2: Thermal stability of HAP and L-arginine functionalized HAP nano-particles.

\begin{tabular}{|c|c|c|c|c|c|}
\hline $\begin{array}{l}\text { Weight Loss }(\Delta M) \\
\text { (\%) In Different } \\
\text { Temperature Range }\end{array}$ & $\begin{array}{l}\text { Pure } \\
\text { HAP }\end{array}$ & $\begin{array}{l}\text { 1-Ar- } \\
\text { HAP }\end{array}$ & $\begin{array}{l}\text { 2-Ar- } \\
\text { HAP }\end{array}$ & $\begin{array}{l}\text { 3-Ar- } \\
\text { HAP }\end{array}$ & $\begin{array}{l}\text { 4-Ar- } \\
\text { HAP }\end{array}$ \\
\hline $\begin{array}{c}\Delta \mathrm{m}(\%) \text { Room } \\
\text { Temperature- } 600{ }^{\circ} \mathrm{C}\end{array}$ & 19 & 24 & 21 & 25 & 28 \\
\hline$\Delta \mathrm{m}(\%) 600^{\circ} \mathrm{C}-1200^{\circ} \mathrm{C}$ & 6 & 4 & 8 & 6 & 3 \\
\hline $\begin{array}{l}\text { Final Residual } \Delta \mathrm{m}(\%) \\
\text { at } 1200^{\circ} \mathrm{C}\end{array}$ & 75 & 72 & 71 & 69 & 69 \\
\hline
\end{tabular}

Table 3: OD value determined in haemolysis test of pure HAP and L-Arginine functionalized HAP.

\begin{tabular}{|c|c|c|c|c|c|}
\hline Sr. No & Sample Name & $\mathbf{D}_{\mathbf{t}}$ & $\mathbf{D}_{\mathbf{p c}}$ & $\mathbf{D}_{\mathbf{n c}}$ & Ratio Z \\
\hline 1 & Arginine & 0.124 & 2.064 & 0.06 & $2.9 \pm 0.5$ \\
\hline 2 & Pure HAP & 0.122 & 2.064 & 0.06 & $2.8 \pm 0.2$ \\
\hline 3 & 1-Ar-HAP & 0.109 & 2.064 & 0.06 & $2.4 \pm 0.2$ \\
\hline 4 & 2-Ar-HAP & 0.084 & 2.064 & 0.06 & $1.2 \pm 0.1$ \\
\hline 5 & 3-Ar-HAP & 0.098 & 2.064 & 0.06 & $1.9 \pm 0.1$ \\
\hline 6 & 4-Ar-HAP & 0.092 & 2.064 & 0.06 & $1.6 \pm 0.1$ \\
\hline
\end{tabular}

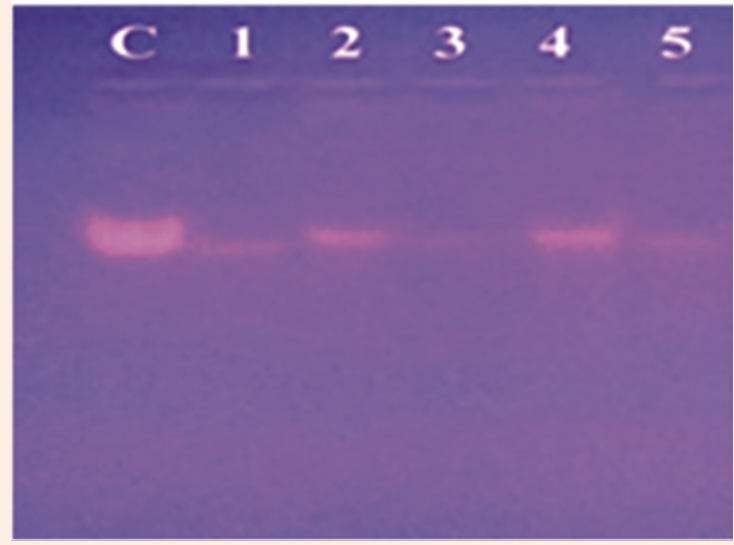

Figure 6: Agarose gel electrophoresis of pure and L- arginine functionalized HAP/ DNA complexes.

Table 4: Quantification of control DNA, Pure HAP and arginine functionalized bound DNA.

\begin{tabular}{|c|c|c|}
\hline Sr. No. & Sample Name & DNA concentration $\boldsymbol{\mu g} / \mathbf{m l}$ \\
\hline 1 & Control & 280 \\
\hline 2 & Pure HAP & 94 \\
\hline 3 & 1-Ar-HAP & 180 \\
\hline 4 & 2-Ar-HAP & 133 \\
\hline 5 & 3-Ar-HAP & 135 \\
\hline 6 & 4-Ar-HAP & 150 \\
\hline
\end{tabular}

\section{Conclusion}

Pure and Ar-HAP nano-particles were successfully synthesized by using surfactant mediated approach. All the samples indicated the nano-crystalline nature with monoclinic crystal structure confirmed by the powder XRD analysis. For higher concentration of L-arginine the presence of brushite phase was noticed. The W-H analysis performed on the powder XRD patterns suggested the presence of strain, which changed with increase in concentration of L-arginine. With comparison to pure HAP the functionalized HAP exhibited less crystallinity and average particle size or crystallite size. The TEM images confirmed the nano size of particles with morphological change from needle to spherical due to the functionalization of L-arginine on HAP surfaces and modifying the growth. Presence of all the functional group related to HAP were confirmed by the FTIR. Further, the successful functionalization of L-arginine on HAP was marked by the existence of $\mathrm{C}-\mathrm{H}, \mathrm{CO}_{2}$ and $\mathrm{NH}_{3}$ vibrations in the FTIR spectrum. Thermal analysis suggested the decrease in thermal stability of HAP due to the presence of L-arginine and progressively decreased with increase in the content of L-arginine. However, the thermal stability of HAP and L-arginine functionalized HAP were above the physiological temperature suggested the safer use at physiological temperatures. Haemolysis study suggested that the samples turned to non-haemolytic from slight haemolytic on increasing L-arginine content. The DNA binding results showed 
that all the samples could successfully bind the DNA, but 1-ArHAP showed the maximum binding efficacy. This finds further applications in gene therapeutic treatment.

\section{References}

1. Ong JL, Chang DC (2000) Hydroxyapatite Coatings in Dental and their Use as Implants: A Review. Crit Rev Biomed Eng 28(5-6): 667-707.

2. Schneittler R, Knoss PD, Heiss C, Sthal J, Meyer P C, et al. (2009) Enhancement of Bone Formation in Hydroxyapatite Implants by rh BMP-2 coating. J Biomed Mater Res B Appl Biomater 90(1): 75-81.

3. Sopyan I, Mel M, Ramesh S, Khalid KA (2007) Porous Hydroxyapatite for Artificial Bone Applications. Sci \& Tech of Adv Mater 8(1-2): 116123.

4. Tiselius A, Hjerten S, Levin O (1956) Protein Chromatography on Calcium- phosphate. Arch Biochem Biophys 65(1): 132 -155.

5. YusufPSM, Dahlan K, Witarto AB (2009) Application of Hydroxyapatite in Protein Purification. Makara Sains 13(2): 134-140.

6. Tan K, Cheang P, Ho IA, Lam PYP, Hui KM (2007) Nano Sized BioCeramic Particles could Function as Efficient Gene Delivery Vehicles with Target Specify for the Spleen. Gene Ther 14(10): 828-835.

7. Mori K, Kanai S, Hara T, Mizugaki T, Ebitani K, et al. (2007) Development of ruthenium-hydroxyapatite-encapsulated Super paramagnetic $\gamma$-Fe203 nano crystallites as an efficient Oxidation Catalyst by Molecular Oxygen. Chem Mater 19(6): 1249-1256.

8. Mahabole MP, Aiyer RC, Ramakrishna CV, Shreedhar B, Khairnar RS (2005) Synthesis, Characterization and Gas Sensing Property of Hydroxyapatite. Ceramic Bull Mater Sci 28(6): 535-545.

9. Yamashita K, Owada H, Umegaki T, Kanazalva T (1990) Protonic Conduction in Yttrium Substituted Hydroxyapatite Ceramics and their Applicability to $\mathrm{H}_{2}-\mathrm{O}_{2}$ Fuel-cell. Solid State Ionics 40: 918-921.

10. Ramovatar M, Kavindra K K, Madhu R, Paulraj R (2012) Effects of Hydroxyapatite Nanoparticles on Proliferation and Apoptosis of Human Breast Cancer Cells (MCF-7). J Nanopart Res 14: 712-723.

11. Yan-zhong Z, Jun Z, Shai-hongn Z, Yan-yan H, Zhi-you L, et al. (2011) Synthesis and Characterization of Arginine-modified and Europiumdoped Hydroxyapatite Nanoparticle and its Cell-viability. Trans Nano Ferrous Met Soc China 21:1773-1778.

12. Luis ZS, Tang SL, Ai ZL (2003) Effect of Hydroxyapatite Nano-particles on Proliferation and Apoptosis on Human Hapatoma BEL-7402 Cells. World J of Gastroenterol 9(9): 1968-1971.

13. Frayssinet P, Nicole R, Methon D (2006) Bone Cell Transfections in Tissue Culture using Hydroxyapatite Microparticles. J of Bio Med Res Part A 79(2): 225-228.

14. Gshalaev VS Demirchan AC (2012) Hydroxyapatite: Synthesis, Properties and Applications, Nova Science Publisher, New York, U.S.A.

15. Aoki H (1994) Science and Medical Applications of Hydroxyapatite, Inc. Euroameric, Tokyo, Japan.

16. Misra D N (1984) Adsorption on and Surface Chemistry of Hydroxyapatite, Springer, New York, U.S.A.

17. Basu B, Katti DS, Kumar A (2010) Fundamentals of Hydroxyapatite and Related Calcium-phosphates in Advance Biomaterials: Fundamentals Processing and Applications, American Ceramic Society, New York, U.S.A.
18. Marchi J, Delfino C, Bressiani J C and Bressiani A H A (2010) Cell Proliferation of Human Fibroblasts on Alumina and HydroxyapatiteBased Ceramics with Different Surface Treatments. Int J Appl Ceram Technol 7 (2): 139-147.

19. Friedmann T, Roblin R (1972) Gene Therapy for Human Genetic Disease? Science 175: 949-955.

20. Feng RL, Maguire KA (2010) Gene Therapy in Parkinson's Disease: Rationale and Current Status. CNS Drugs 24(3):177-192.

21. Ott MG, Schmidt M, Schwarzwaelder K, Stein S, Siler U, et al. (2006) Correction of X-linked Chronic Granulomatous Disease by Gene Therapy, Augmented by Insertional Activation of MDS1-EVI1, PRDM16 or SETBP1. Nat Med 12 (4): 401-409.

22. Maguire AM, Simonelli F, Pierce EA, Pugh EN, Mingozzi F, et al (2008) Safety and Efficacy of Gene Transfer for Leber's Congenital Amaurosis. New Engl J of Med 358(21): 2240-2248.

23. Tebas P, Stein D, Tang WW, Frank I, Wang SQ, et al. (2014) Gene editing of CCR 5 in Auto logous CD4 T Cells of Persons Infected with HIV. New Engl J of Med 370 (10): 901-910.

24. Bessis N, Garciacozar FJ, Boissier MC (2004) Immune Responses to Gene Therapy Vectors: Influence on Vector Function and Effect or Mechanisms. Gene Ther 11: S10-S17.

25. Niidome T, Huang L (2002) Gene Therapy Progress and Prospects non viral vectors. Gene Ther 9(24): 1647-1652.

26. Jackson DA, Juranek S, Lipps HJ (2006) Designing Non Viral Vectors for Efficient Gene Transfer and Long-Term Gene Expression. Mol Ther 14(5): 613-626.

27. Groot KD (1980) Bioceramics Consisting of Calcium Phosphate Salts. Biomaterials 1(1): 47-50.

28. Venkatesan P, Puvvada N, Dash R, Prashant Kumar BN, Sarkar D, et al (2011) The Potential of Celecoxib Loaded Hydroxyapatite-Chitosan Nano-Composite for the Treatment of Colon Cancer. Biomaterials 32(15): 3794-3806.

29. Yin M, Yin Y, Han Y, Da H, Li S (2014) Effect of Uptake of Hydroxyapatite Nano-particles on Human Hepatoma Cells Adhesion and Proliferation. J of Nanomater. 1-7.

30. Bertran O, Valle LJ, Revilla-Lopez G, Chaves G, Cardús L, et al. (2014) Mineralization of DNA into Nano-particles of Hydroxyapatite. Dalton Trans 43(1): 317-327.

31. Futaki S, Ohashi V, Suzuki T, Niwa M, Tanaka S, et al. (2001) Stearylated Arginine-Rich Peptides: A new class of Tranfaction Systems. Bioconjug Chem 12(6):1005-1011.

32. Palazzo B, Walsh D, Iafisco M, Foresti E, Bertinetti L, et al. (2009) Amino acid Synergetic Effect on Structure, Morphology and Surface Properties of Bio-mimetic Apatite Nano-crystals. Acta Biomater 5(4):1241-1252

33. Lee WH, Loo CY, Zavgorodny AV, Rohanizadeh R (2011) High Protein Adsorptive Capacity of Amino-acid Functionalized Hydroxyapatite. J Biomed Mater Res A 101(3) 873-883.

34. Gonzalez MR, Chane CJY, Vignaud EA, Lebugle, Mann S, et al. (2004) Synthesis and Characterization of Amino-acid Functionalized Hydroxyapatite Nano-rods. J Mater Chem14: 2277-2288.

35. Boanini E, Fini M, Gazzano M, Bigi A (2006) Hydroxyapatite Nanocrystals Modified with Acidic Amino-acids. Eur J Inorg Chem 10:48214826. 
36. Tank KP, Chudasama KS, Thaker VS, Joshi MJ (2013) Cobalt Doped nano Hydroxyapatite: Synthesis, Characterization, Antimicrobial and Haemolytic Studies. J Nanopart Res 15:1644-1654.

37. Chudasama KS, Thaker VS (2012) Screening of Potential Antimicrobia Compounds Against Xanthomonas Campestris from 100 Essential Oils of Aromatic Plants used in India: an Eco-friendly Approach. Arch. Phytopathol. Plant Prot 45(7): 783-795.

38. Tank KP, Sharma P, Kanchan DK, Joshi MJ (2011) FTIR, powder XRD, TEM and Dielectric Studies of Pure and Zinc Doped NanoHydroxyapatite. Cry Res Technol 46(12) :1309- 1316.

39. Mote VD, Purushotham Y, Dole BN (2012) Williamson-Hall Analysis in Estimation of Lattice Strain. J Theor Appl Phys 6(6): 2251-2259.

40. Solanki PD, Vasant SR, Joshi MJ (2014) Synthesis, Crystal Structure, Spectroscopic and Thermal Analysis of Strontium Pyrophosphate Dihydrate Nanoparticles, Intl J Ceramic Technol 11(4): 663-669.

41. Tank KP (2013) Synthesis, Characterization and Inhibition Study of Pure and Doped Nano-Apatites, Ph.D. Thesis, Saurashtra University, Rajkot, India.
42. Murray MGS, Wang J, Pontoon CB, Marquis PM (1995) An Improvement in Processing of Hydroxyapatite Ceramics. J Mater Sci 30(12): 3061-3074.

43. Dobrovolskaia MA, Clogston JD, Neun BW, Hall JB, Patri AK, et al. (2008) Method for Analysis of Nano Particle Haemolytic Properties In Vitro. Nano Lett 8(8): 2180-2187.

44. Tank KP (2014) Nano Hydroxyapatite and Silver Doped nano Hydroxyapatite. Scholar's Press, Saarbrücken, Germany.

45. Kandori K, Toshima S, Wokamura M, Fukusumi M, Morisada Y (2010) Effects of Modification of Calcium Hydroxyapatites by Trivalent Metal Ions on The Protein Adsorption Behavior. J Phys Chem B 114(7): 2399-2404.

46. Uddin $\mathrm{MH}$, Matsumoto $\mathrm{T}$, Ishihara S, Nakahira A, Okazaki M, et al. (2010) Apatite Containing Aspartic Acid for Selective Protein Loading. J Dent Res 89(5): 488-492.

47. Andrews-PC, Fradosh DW, Thorpe J, Williamson SJ (2010) Hydroxyapatite-Mediated Separation of Double-stranded DNA Single-stranded DNA, and RNA Genomes from Natural Viral Assemblages. Appl Environ Microb 76(15): 5039-5045. 